of magnesium was followed by an action in from five to ten minutes. Tarious solutions and drugs were tried and it was found that two drachms of olive oil was the most suitable. This acted perfectly and she was discharged on May 4th. I saw her about six months later and I have heard from her medical attendant quite recently. She continues perfectly well, the opening remains patent and gives her no trouble, perfectly well, the opening remain

CASE 3. - The patient, a female, aged 66 years, was admitted to the infirmary in May, 1906, on account of mucous colitis and constipation. infirmary in May, 1906, on account of mucous colitis and constipation. Her medical attendant was desirous that the operation of appendicostomy should be performed upon her. She was a well-nourished woman. of constipation, and of the passage of mueus. The abdomen was not distended or tender. Per rectum and per vaginam examination did not reveal anything. A large quantity of mucus was passed with the reveal anything. A large quantity of mucus was passed with the motions.

An operation was performed on May 11th in the same way as in Case 1. The appendix was cut off level with the skin on the fourth day and irrigation was then commenced. The administration of five pints of saline solution followed by two pints of solution of silver nitrate (one grain to a pint) acted immediately and brought away a large quantity of mucus and fæces. This was continued daily. Three days later the opening into the appendix was found to have retracted below the skin to the level of the deep fascia, probably owing to the commencement of irrigation before it was sufficiently adherent. It was still quite easy for us to pass the catheter but it would have been difficult for the patient herself to have done so. On June 3rd (just over three weeks ater) it was noticed for the first time that some of the Huid injected escaped by the side of the catheter. This amount increased daily and by the 7 th practically all the fluid injected increased daily and by the 7 th practically all the fluid injected returned through the opening. This caused a suspicion of some obste 9 th an incision was made in the left side to expose the sigmoid flexure. A malignant stricture was discovered and a colotomy was performed. The patient was discharged lived about six months and that the appendicostomy opening closed up and did not give any trouble.

up and did not give any trouble. infirmary in February, 1907, on account of obstinate constipation. She had had three attacks of pain in the right iliac region since September. Examination revealed some tenderness on deep pressure over the region of the cæcum. Nothing was discovered per vaginam or per rectum

On Feb. 5th the appendix was exposed through the usual incision. It contained a small concretion and it was brought out and beld in position by a pin through its mesentery. The wound was closed in layers, taking care not to strangulate the appendix or its mesentery. On the third day following the appendix with its contained concretion was cut off level with the skin. Irrigation was commenced on the day following. The patient was discharged on March 16th. She was much improved in health and could manage the irrigation quite easily. She has been seen several times since and she continues the irrigation which keeps her bowels regular and she feels quite well.

CASE 5.-The patient, a male, aged 50 years, was admitted to the infirmary in January, 1908. He had suffered for several years from infirmary in $J$

An operation was performed on Jan. 8th. The appendix was exposed An operation was performed on Jan, 8th. The appendix was exposed through the usual incision, three inches long, and the contents of the curved, necessitating partial division of its mesentery; it was fixed in the wound as in the previous case; it was cut off level with the skin the wound as in the previous case; it was cut off level with the skin
on the 1lth, and irrigation was commenced. Following this there was on the 1lth, and irrigation was commenced. Following this there was india-rubber catheter being kept in position. The effect of the irrigation was immediately satisfactory and all the bowel symptoms have disappeared.

In considering these five cases I think I can fairly claim that each of them derived benefit from the operation. In Case 3 it enabled us to diagnose the cause of the mucous colitis from which the patient had suffered and to perform a colotomy for its relief. The patient had been examined by several physicians without the condition being suspected and but for the appendicostomy it would have remained undiscovered until complete obstruction had occurred, when the risk of operation would have been far greater. The case indicates the importance of bearing in mind that mucous colitis may be only a symptom of organic disease. It is for this reason that I advocate intra-abdominal exploration at the time of operation. It has been suggested that the appendix can be dilated sufficiently to act in lieu of a colotomy. This would have been a suitable case for such a proceeding, but I was unable so to dilate it. From my experience I do not think that such a procedure is practicable in many cases.

The result of the treatment in the other four cases has been satisfactory so long as it has been continued. The mucus has disappeared within three weeks of irrigation. The fluid used consisted of two pints of saline solution followed by one pint of silver nitrate solution (one grain to the pint). At the end of three weeks the latter was omitted and a pint of saline solution only was used. In Case 2 it was found that two drachms of olive oil were sufficient to keep the bowels acting. I have seen this patient within the last month and find that this is still satisfactory.

Unfortunately many of these subjects are neurotio and it may be impossible to persuade them to continue the irrigation regularly. If they do not, the orifice is liable to contract; this is the more likely if there has been any wound infection at the time of operation. It is a difficult matter to dilate the orifice and when it is accomplished it will probably be allowed to contract again. The patient in Case 1 was an example of this class. In such cases a more radical procedure is indicated, but the preliminary performance of this operation does not materially add to the risk and gives patients a chance of relief by an operation with a lower mortality.

In none of the cases has there resulted the slightest discomfort. The orifice does not emit any discharge and is easily kept clean. The mucous colitis is easily controlled and the action of the bowels can be regulated with certainty.

Kidderminster.

\section{CONGENITAL HYPERTROPHIC STENOSIS OF THE PYLORUS AND ITS MEDICAL} TREATMENT.

BY GEORGE CARPEN'TER, M.D. LOND.,

CHAIRMAN OF COUNCLL OF THE SOCIETY FOR THE STUDY OF DISEASE IN CHILDREN; MEMBRE OORRESPONDANT DE LA SOCIÉTÉ DE PÁDIATRIE DE PARIS.

FOR some time I have been on the watch for a clinical example of pyloric obstruction in an infant which would convince me as to its undoubted hypertrophic nature and which would respond to medical treatment. The case which I presently shall relate satisfies those requirements. I have been well acquainted with dyspeptic troubles in infancy without pyloric hypertrophy which clinically give all the symptoms of that complaint except one important finding, and that is the pyloric tumour. Cases such as these I, too, have had my successes with medically. But if I were to enumerate all $\mathrm{my}$ experiences in that respect, then $I$ also would be able to bring to your notice a magnificent array of cases of congenital hypertrophic stenosis of the pylorus in place of this solitary example of a successful case medically treated.

It is but the other day, figuratively speaking, that serious attention was drawn to this condition, and the great number of cases that have fallen to the share of, and have been recorded by, some observers must be due to the inclusion in their statistics of the functional with the organic variety, of the very common with the rare, for it cannot be allowed that hypertrophic stenosis is any other than a rare condition. On the other hand, infantile cases of functional gastric disturbance with symptoms suggesting pyloric stenosis are very common. Some such explanation must be held accountable for the high percentage of cases which have fallen to the share of some writers on this subject in so short a time. But I must confess that I did not think it possible to cure such examples of congenital hypertrophic stenosis of the pylorus as have come within my clinical experience without surgical aid. In the cases of that complaint which I have treated the pyloric tumour was hard like gristle, cut like the cartilage of the knee, was felt through the abdominal wall, the infants were operated upon, and they all died. In the case which I am about to relate the patient presented symptoms and physical signs precisely similar to, and identical with, those just enumerated. By reason of his wasted state and the poor condition of his vitality he was not fit to undergo surgical operation and would, I doubt not, have died if he had been operated upon.

It is remarkable how many recorded cases there are where no pyloric tumour was felt and where the typical appearance was found either at operation or in the postamortem room. But notwithstanding these repeated failures to detect the tumour during life, I must confess that the diagnosis of congenital hypertrophic stenosis of the pylorus does not satisfy me unless the tumour be felt. Perhaps the failure to find it may in some cases have been due to want of experience of what to feel for, but I think that if greater care had been exercised in making the abdominal examinations the little tumours would not have so frequently remained undiscovered. Granted, however, that due care had been taken, I think I can offer another explanation for failure to feel the tumour. By the usual method of examination--that is, by palpationthe tumour is apt to recede from the fingers and to drop deep down into the abdominal cavity. Now, if in addition to the usual method of abdominal exploration the examiner grasps the abdominal parietes and the underlying parts with the

1 A paper read before the Society for the Study of Disease in Children on Jan. 17th, 1908. 
fingers and thumb from right to left and vice versî, he will the more readily find the characteristic small hard mass, and not only detect it but gauge its size and shape and even note the accompanying induration of the stomach walls. In thin babies no difficulty should be experienced, and a plump healthy infant with this condition is not likely to come under medical observation. Prior to my own experience about to be related, although preserving a perfectly open mind on the subject, I doubted whether the true explanation had been arrived at for the pyloric tumours which had been found in the cases treated successfully medically. But now I no longer have any doubt, and I am perfectly satisfied that cases of congenital hypertrophic stenosis of the pylorus can be relieved by medical means and without the surgeon's aid.

Hopeless in regard to medical treatment as the typical hypertrophied pylorus appears to be in the post-mortem room-the tightly shut orifice, the thick gristle-like walls the cervix and os uteri-like appearance on its duodenal aspect, its capacity securely to hold a dilated stomachful of water-I do not think this after-death state denotes its natural condition during life. I think that tight post-mortem contraction of the hypertrophied circular muscular fibres occludes the pylorus, and this prevents the exit of water when tested in the usual way. Indeed, quite apart from other reasons I know that this must be so, because I have seen the channel patent (No. 4 catheter) during life, even in an extreme case of this interesting condition.

There are two hypotheses as to the causation of congenital hypertrophic stenosis of the pylorus-viz., (1) that this condition is a muscle hypertrophy not only of the pylorus but of the rest of the stomach, and that it is secondary to a functional disturbance (Heubner ${ }^{2}$ ); and (2) that it is a primary malformation or new growth. Heubner does not state definitely whether his conclusions were based upon his own post-mortem experience; in any case he could not have performed more than one necropsy as he had only one death. And secondly, from the remarks in his pape which was read before the Children's Section of the seventyeighth Versammlung Deutscher Naturforscher und Aerzte in Stuttgart, he gives the impression that he bases his conclusions on necropsies performed by Wernstedt. He claims 49 cases out of a clinic of 10,000 children. In regard to the two views I am in favour of the congenital hypothesis for these reasons : (1) the condition has been found in the fotus (Dent); (2) symptoms frequently arise immediatiely after birth in cases where it is known to exist; and (3) the associated muscle hypertrophy of the stomach is not a general hypertrophy of the organ, or if it be a general hypertrophy of the viscus the part near the pylorus, to the extent of a quarter or one-third of the pyloric end, is immensely thicker in comparison. The stomach being a hollow viscus I think hypertrophy would be general rather than partial if that hypertrophy were due to increased work. It is so, as a general rule, in the bladder with a large prostate, the nearest resemblance to it that I can think of, whatever may be the exceptions to that rule, if there be any. I have made microscopical examinations in three cases and I have found in the pylorus thickening of all the muscular layers, including the muscularis mucosæ. The longitudinal fibres were two or three times larger than they should have been, but they were not hypertrophied to the same comparative degree as the circular, which were very powerful. Further, there was an increase in the fibrous tissue, and the submucous layer was larger and thicker than normal. The mucous membrane was healthy. The thickened pylorus ended abruptly at the duodenal side (cervix uteri-like appearance), but gradually tapered off into the stomach walls on the opposite side. On the outside it was constricted in the centre. In the stomach of one case all the layers were hypertrophied, but especially in the pyloric fourth, and the circular fibres were equal to the two others combined. In the others there was considerable hypertrophy of the stomach walls of the pyloric third or fourth. The submucosa was thicker than natural. The mucous membrane was natural. ${ }^{3}$

In regard to naked-eye appearances in this condition the stomach may or may not be dilated, and it is not necessarily dilated in even pronounced instances. On the other hand, it may be very large. Peristalsis may or may not be seen. This occurs in the undilated as well as in the dilated organs,

- Monatschrift für híndexheillkunde, Band v., \$. 355, 1907

3 Reports of the Society for the $\$$ tudy of Disease in Children roports the study and is best seen when the infant is marasmic, and it is a late, not an early, symptom.

Although symptoms in cases of hypertrophic stenosis often start from the birth, yet this is by no means invariably the case, and sometimes it is one, two, three, four, or more weeks before their onset. The infant then commences to vomit If this be not checked other symptoms rapidly supervene and steady deterioration results. When vomiting occurs in grim earnest, constipation and scanty urine are its associates. Vomiting may be both irregular as to time and in quantity the vomit may be small or consist of accumulated feeds. There may be nothing special about the act or the stomach contents may be pumped up violently on to the floor. In a well-marked case bile is absent from the vomit. The stools may be meconium-like, sage green, dark green, dark brown, or tarry. But even these may disappear and be followed temporarily by natural motions. In some cases the symptoms that attract most attention are constipation and marasmus with a dyspeptic background. Prior to all these symptoms, however, it often happens that the child has enjoyed good health and there has been no occasion to suspect any organic gastric malady. Perhaps the baby has been taken from the breast and put on the bottle, and then its troubles began. Although the infant in such cases has displayed no symptoms, I do not think that there is any reason to doubt that the thickened pylorus has been comfortably tucked away all the time. Granted that this be so, why does it suddenly become troublesome?

Cases with classical symptoms of stenosis of the pylorus have succumbed to the malady and post mortem the pylorus has been found normal. The explanation that has been given for cases such as these is that the patients were suffering from pyloric spasm. Granted that pyloric spasm can kill an infant with a healthy pylorus it can as readily accomplish the act with a hypertrophied pylorus. Graft the spasmodic affection on the organic and the explanation of the symptoms is at hand. Perhaps the over-powerful strongly acting pylorus causes congestion or cedema of the overlying macous membrane with blocking of its lumen, or there may be other explanations for its local congestion, analogous to the congestion of the mucous membrane covering the urethral stricture of a Saturday night reveller. Judged by the irritability of the stomach displayed in these cases the speedy response by waves of gastric peristalsis of regular or irregular rhythm to even so little as the lightest tap over it, it is likely that the pylorus also is in an equally excitable condition. It may be that in such circumstances the mere mechanical irritation of the food tends to keep the fylorus in a constant state of reflex spasm, let alone any toxic action on the muscles or nerve centres that might be supposed to arise from the complex chemical products retained in the stomach. But whatever may be the explana. tion of the obstruction at the pylorus I have no doubt that the causes for it are as complex and multifarious as are the causes for gastric disturbances that occur in the dyspeptic infant, for it is the dyspepsia that is at the bottom of it, and which is the important factor in these cases. This is not based solely on hypothetical conditions, for have we not pathological evidence to support it? A suckling infant under the care of Bloch ${ }^{4}$ was completely cured after having had four weeks' symptoms of congenital pyloric obstruction; he succumbed six months later to an attack of acute enteritis. The pylorus was found just as hypertrophied and just as constricted as in children who die from pyloric stenosis. A study of the vomited matters has thrown no special light on the condition. In some cases there has been no free hydrochloric acid, in others this has been present, in others the vomit has been "intensely acid and sour-smelling," and again in others mucus and lactic acid have been detected, but no free hydrochloric acid.

Dismissing the question of hypertrophic stenosis of the pylorus from the mind for the moment and turning to the infant with a normal pylorus we are daily faced by the problem of how to cater for infants with weak digestions. It is occasionally brought to our notice that the ideal infant food, the mother's milk, is not always the innocuous babygrowing material that it is supposed to be-quite the opposite. There are some infantile digestions that cannot tolerate mother's milk, be it that of the child's own mother or that supplied by foster-mothers-not one foster-mother but a succession of them. Such infants become sick and they

4 Quoted by R. Romme, Jahrbuch ftir Kinderhoilkunde, 1907, vol. $x v_{0}$, p. 477 . 
waste and would die, and yet they straight away make progress on a preparation of con's milk that one would not have advocated on theoretical grounds. There can be no question that some milks are toxic in their action, be they breast milk or cow's milk, and feeding with them brings about reflex muscular action and all the symptoms of congenital hypertrophic stenosis of the pylorus.

Dyspepsia in infants is a thing to be avoided, and such dyspepsia is often manufactured by the ignorance and stupidity of those in charge of infants.

If the feeding of the normal infant is a problem in some cases, it becomes additionally so if there happens to be bypertrophic stenosis in the background. In the cases which we are treating daily without this deformity, we are prepared to struggle on and do our best to relieve symptoms. There is no reason therefore why despondency should set in when treating cases of hypertrophic stenosis of the pylorus because they do not quickly answer to treatment. They must be looked upon as difficult medical cases from the outset and dealt with accordingly.

The records of the surgical treatment of this complaint show that the infant does not readily tolerate plastic operations on the abdominal viscera, even at the most skilful and the most expeditious hands. Nor has the medical treatment hitherto been anything to make a boast about. Nevertheless we must for the future, I think, look upon surgery as a dernier ressort and not as the sheet anchor of treatment. It is hard upon the surgeons, I admit it, to ask them to galvanise into life a moribund athrepsic infant, and failing in that to take a share in the responsibilities and in the obsequies, but I think in the interest of the patient the surgeon must be thought of late in the case. But once let the physician realise that these cases are not untreatable medically, and there will in the future be more medical successes and fewer surgical failures. What the future will have in store for the cases of hypertrophic stenosis that have been cured medically remains to be seen. In regard to this point, however, it is not uninteresting to learn that Seefisch found that in three cases that responded to this treatment operation became necessary before the children reached the age of 12 years.

Surgery as a mode of treatment for pyloric spasm is neither necessary nor advisable. To operate on such a case would be on a par with performing tracheotomy for the cure of laryngismus stridulus. It is for the purpose of preventing unnecessary operations as well as from the desire to diagnose the case correctly that I attach very great importance to the discovery of the pyloric tumour, and had more attention in the past been paid to its detection there would have been fewer cases on record of congenital hypertrophic stenosis.

Finally, what should be the treatment? It must be conducted on the broad, general principles that experience has taught us to be of value in the uncomplicated complaint. Muscular and nervous hyper-excitability of the organ may be fought by antispasmodics, such as cocaine, opium, chloral, bromide, antipyrin, belladonna, camphor, and sulphocarbolates. I have no special partiality for any of these drugs and I have no supreme faith in their performances. The secret of success in all medical treatment of dyspepsia in infants lies not so much in its drug treatment as in the discovery of the milk best suited to the child. When bottlefeeding is compulsory the selection of just the right form and the right dilution of cow's milk requires careful study, but above all things it must be clean. A baby's stomach will deal efficiently enough with a poor milk, but it will immediately resent the stale and the dirty article. And not only should it be clean, but it should be undoctored. The food that is selected should be one that leaves a small residue-one that the gastric juice can readily dissolve. Large lumps of curd in the stomach are fatal to progress.

Regular meals are no less important than restricted meals, and not only are meals that are too bulky to be carefully avoided but the meal must be administered slowly. The dyspeptic infant becomes an inveterate food-bolter, and a meal that is dumped down into the infant's stomach is bound to disagree. The man who is in a hurry to change the dietary because the infant's stomach does not immediately respond to his treatment will never succeed. Success can only be compelled by shaping a course and intelligently sticking to it. It will be found on inquiry that those who claim that they have tried everything have really tried nothing. Ringing the changes on $a$ variety of foods invites dyspepsia, it does not cure it, and such panic-bred dietaries must be avoided.

Abdominal massage in the direction of the pyloric outlet has proved efficacious in at least one case. But in regard to topical treatment gastric lavage has a well-merited reputation. Thorough stomach washing with warm normal saline solution should be used twice a day until the complaint shows decided signs of improvement, when it may be tried once a day. That the remedies are working satisfactorily can be seen by the improved condition of the stools. And there are two other precautions that must be taken-viz., to keep the infant's stomach warm and not to upset his digestion by starchy foods.

But when is the surgeon to be called in? In the present state of knowledge, to assert that the surgeon should never be called in is perhaps not warranted by the facts, but nevertheless I think the advice should be hardly ever, and that the physician will best serve his patient by not being in too great a harry to shift his responsibility on to his surgical colleague.

On May 22nd, 1907, I saw a male infant, aged two months, in consultation with Dr. D. J. Munro, of Brixton. The bistory given was typical of the condition of pyloric stenosis. The patient would keep down two or three feeds and then would vomit what appeared to be the whole amount previously taken. He was constipated, had gradually whole amount previously taken. He was constipated, had gradually
lost ground from the first week of birth, and in spite of being fed on a variety of foods "vomited everything." Various proprietary foods variety of foods "vomited everything." Various proprietary foods the same result: persistent vomiting followed, accompanied by constipation and the passage of scanty concentrated urine. At a week old the child was breast-fed, took food well, weighed about 7 pounds, and did not vomit, but owing to the mother suffering from a slight attack of rheumatic fever he had to be artificially reared, with the result just
related. He was very emaciated when I saw him and seemed so ill related. He was very emaciated when I saw him and seemed so ill low and feeble, the respirations were very shallow, the anterior ontanelle was depressed, and the temperature was subnormal. The child was too weak to cry; he opened his mouth as though to cry but no sound came from the lips. He weighed 5 pounds 13 ounces. The vomitinc was very persistent and violently expulsive and the bowels were almost absolutely confined.

An abdominal examination left no doubt in my mind as to the nature of the complaint. There was an indurated pylorus of the most typical feel. The lump was located above and to the left (examiner's) of the umbilicus; it was deep down in the abdominal cavity, could be grasped between the fingers and thumb on deep manipulation, was as large as an almond-nut, and felt as hard as gristle. Further, there was on abdominal manipulation obvious gastric peristalsis terminating in the direction of the lump aforesaid. Otherwise there were no physical gigns, but there was a right inguinal hernia which had appeared a week, but ther birth. The physical condition of the child was so weakened that it appeared to us that to submit him to surgical operation was that it appeared to us that to submit him to surgical operation was with the parents consent, he should be medically treated, that the diet with the parents consent, he should be medically treated, that the diet should be whey, and that the stomach should be washed out daily. On the night of my visit Dr. Munro washed out the stomach with a 0.5 per cent. solution of common salt; this was followed by a four-ounce feed of whey, and subsequently two-ounce feeds every two hours were administered. On the day following and on subsequent occasions the wash was made of sodium sulphate, 0.5 per cent., and sodium bicarhonate, 02 per cent., which had the immediate effect of causing regular actions of the bowel. Four-hourly drop doses of laudanum were also ordered. There then had been no sickness tor 24 hours and 14 ounces of whey had been retained. On May $24 \mathrm{th}$, the second day of treatment, the infant was sick twice following cod-liver oil by the mouth, but 15 ounces of whey were retained. He also passed two dark green offensive motions, the first for four days. On the next day he was ordered teaspoonful doses of olive oil by the rectum, and in place of the drop doses of tincture of opium (which were making him much too somnolent) half-drop doses were substituted, combined with drop doses of tincture of belladonna. whe injections of olive oil were mostly all absorbed, but sometimes The injections of olive oil were mostly all absorbed, but sometimes bowels were opened about once daily and the motions were mostly bowels were opened about once daily and the motions were mostly retained daily the following quantities of whey-viz., 143, 203, 19, 15, $18,19,17,16,16 \frac{1}{4}$ and 17 ounces. On the fourth day after ommencing treatment he had lost two ounces in weight, but commencing treatment he had lost two ounces in weight, but the last five days. The child was sick twice on May 25th, three times on the $26 \mathrm{th}$, twice on the $27 \mathrm{th}$, twice on the $28 \mathrm{th}$, once on the 29th, once on the 30th, and then not again for eight days, when on une 7 th he vomited twice. He was fattening visibly. Such was the condition of the patient on June 7 th but for several days he had suffered from erythema and cedema and the possibility of this cutaneous disturbance being due to the olive oil injections occurring to Dr. Munro they were discontinued. But the rash still continued to appear for three or four days, so the rectal injections were recommenced but then given once daily only. According to the nurse's description the rash "seemed to appear just after the olive oil injections." The lips became swollen, red patches appeared over the face, rather like port wine stains, and the hands and feet were red and swollen. Besides the swelling of the hands and feet swelling was noticed on the right side of the sacrum; it was, quoting the nurse's words, "quite dropsical." and about two days later it spread over the body. The infant increased in weight, an increase which was thought to be only owing to the swelling just mentioned. By June 5th there was a good deal of dropsy of the neck. He coughed a lot over his feeds and there seemed great difficulty in swallowing and also in breathing. The child was propped up with pillows and often had to be held up by the feet as he choked and "went 
accountable for these troubles. On the 6th the opium was discontinued (one and a half minims of tincture of digitalis being substituted). The infant then became brighter and cried more after its discontinuance. On the 7 th I again saw the patient with Dr. Munro. OEdema was at that time a marked feature though less extensive than it had been. The erythema had disappeared. The urine contained two parts per 1000 of albumin but there were no casts; it was slightly alkaline when passed and deposited a slight precipitate of earthy phosphates. Dr. Munro subsequently examined the urine and came to the conclusion that there was no deficiency of chlorides. Dr. Munro reported on the 11th that the oedema had quite disappeared since omitting the laudanum. Magnesium sulphate, 0.5 per cent., was now used by him for lavage with the idea that the magnesium base would assist in the elimination of chlorides. Starting on June 8th the child was fed on "humanoid" milk, an Aylesbury dairy company product. He took it well but only in small quantities; 15 grains of cane sugar were added to each feed. He appeared to be more satisfied with the new diet, and he slept well, but the weight fell to 5 pounds $12 \frac{1}{2}$ new diet, and he slept well, but the weight fell to 5 pounds $12 \frac{1}{2}$ every 36 hours in place of every 24 hours, as was previously the every 36 hours in place of every 24 hours, as was previously the
case. On the 14th Dr. Munro reported that the patient was case. On the 14th Dr. Munro reported that the patient was more than two ounces per feed." He was still losing weight, having dropped to 5 pounds 7 ounces-less than ever. He was sick while being fed once, the first time for a week, there having been no sickness since the 7 th. He was ordered a milk-and-water mixture-one part milk and two parts water-erery two and a half hours, from two to three ounces at a feed, and to three of the bottles a teaspoonful of eream was added. On the 15 th, as the mother was anxious for it, a wet nurse was obtained and mixed feeding was instituted. The infant was sick once on the 16th and three times on the 18th; on this latter occasion coffee-ground vomit occurred, which was thought to be due to cracked nipples. The wet nurse not being a success was discontinued. Lavage was discontinued on the 20th. The child was sick once on the 21st, but not again until the 28th, when he was sick once and then for the last time. had lost and gained on an average an ounce a day. He suffered a good deal with flatulence all through the illness, especially after food, and sometimes would cry nearly all day, as if in pain. (After wearing a woollen truss, which was applied in the midale of August, he cried ever so much less.) He perspired a

The weight of the patient on June $14 \mathrm{th}$, when milk-and-water feeding was started, was 5 pounds 7 ounces, and on July 8 th it was 6 pounds 12 ounces. Dav by day increasing quantities of milk-andwater were taken; on June 14 th the amount was 18 ounces, while on
July 6th it was 30 ounces. While on whey the bowels were opened once daily and the motions were green but after the child had been fed on milk and water for a week the stools became quite natural and there were from two to four motions in the 24 hours. Week by week the patient continued to gain ground and by July 27th, when the rectal injections of olive oil were discontinued, he weighed 8 pounds 1 ounce. On August 22nd, when brought back to London, he weighed 9 pounds 8 ounces, and on the $27 \mathrm{th}$, when the nurse left, he weighed 10 pounds and was steadily graining ground every day. In the middlo of September he suffered from spongy tender cums for a week but since impresing the necessity for antion since impressing the necessity for antiscorbutic foods upon the parents 16 pounds at seven and a half months and was a jolly, normal baby, and he still (January, 1908) continues to thrive.

\section{A SUGGESTION FOR TREATMENT IN DELAYED CHLOROFORM POISONING.}

By A. P. BEDDARD, M.A., M.D. CANTAB., F.R.C.P. LoND, ASSISTANT PHYSICIAN TO GUY'S HOSPITAL; PHYSICIAN TO THE WEGT LONDON HOSPITAL.

AlThougH patients suffering from delayed chloroform poisoning may recover spontaneously the literature of the subject shows that the prognosis is bad, which is only another way of saying that the treatment, whether preventive or curative, is unsatisfactory. The clinical symptoms and post-mortem appearances are constant and well established, but their interpretation is still a matter of controversy. Nevertheless, for the purposes of treatment it is necessary to adopt some working hypothesis of the pathology of the condition.

The curative treatment most frequently adopted has apparently been the use of alkalies. This presupposes that an acute acid intoxication of the body is at least an important cause of the symptoms and fatal result. And we must consider whether this is likely to be true. There are many conditions known in which metabolism is so deranged that organic acids produced in the body escape oxidation and are excreted in abnormal quantities in the urine. This state of things is termed acidosis. The body has to provide bases in order to neutralise these acids, and for this purpose it uses either $\mathrm{NH}_{3}$, the normal precursor of urea, or failing a sufficient supply of $\mathrm{NH}_{3}$ the inorganic bases in the tissues. The organic acids, such as lactic, $\beta$ oxybutyric, diacetic, \&c., which are intermediate products of metabolism, are not in themselves poisonous; their power of doin the body harm is confined to their action as acids and as long as the body provides sufficient base to neutralise them their presence will not produce symptoms. In other words, acidosis is not a poisoning of the body by acids and it is only when the supply of base begins to fail that acidosis passes into acid intoxication. We know that a high degree of acidosis by the acetone bodies may exist for weeks and even for years, as in acute starvation and severe diabetes, without causing any symptoms of acid intoxication ; in fact, we do not know any condition whose symptoms and fatal issue are probably due to an acute acid intoxication, with the single exception of diabetic coma. Even in such a severe disease of the liver as acute yellow atrophy, although an acidosis is certainly present, death supervenes far too rapidly for the symptoms to be due to the acidosis passing into an acid intoxication. This is still more obviously true of poisoning by phosphorus, in which the acidosis is less severe. It is further remarkable what severe and widespread changes may exist in the liver without causing acidosis. For instance, in poisoning by hydrazine, which induces changes in the liver similar to those of phosphorus, no acidosis is present; and the same is true of animals in which multiple necroses of the liver have followed the injections of hæmolytic sera. From these con. siderations we have to conclude that alkalies could not be of much value in the treatment of delayed chloroform poisoning and clinical experience confirms it.

The weight of evidence is in favour of the view that the poisoning by chloroform is the cause not only of the symptoms but also of the microscopical changes found in these cases. It is, however, manifestly necessary to believe that certain individuals are highly susceptible to the action of chloroform, and the cause of this state of things is equally unknown, no matter whether we call it idiosyncrasy or believe that the vitality of their protoplasm has received some previous injury which has made it unduly susceptible to the action of a general protoplasmic poison like chloro. form. Numerous experiments on animals have shown that the action of chloroform on cells is similar to that of phosphorous, arsenic, and other general protoplasmic poisons. Although we do not know how any of these poisons injure cells it is necessary to form some working conception of what changes they induce in the metabolism of the body in addition to the changes caused by the concomitant starvation. The broad facts seem to be as follows. Nitrogenous metabolism is increased-that is to say, there is an increased breaking down of tissue proteid. But the metabolism of nitrogenous substances is also disturbed so that products of proteid catabolism leave the body no longer in a fully oxidised state; consequently the cells have lost to a corresponding degree the power of obtaining energy from proteid. The hepatic glycogen rapidly disappears and to a less extent that of the muscles and other cells; and further the total quantity of carbohydrate in the body is decreased. But in poisoning by chloroform the liver has not necessarily lost the power of forming glycogen, as can be shown by feeding the animals with dextrose. It is therefore clear that carbohydrate metabolism is increased greatly at first and that since the store of carbohydrate material in the body is relatively very small, this increased utilisation must soon come to an end. The facts in regard to the metabolism of fat are well estab. lished. Microscopically the cells of the liver, muscles, and kidneys appear to be loaded with fat. In the case of the kidney, however, there is no actual increase of fat; the appearance of the cells is due to a change in their protoplasm whereby fat in combination and thereby masked and invisible becomes obvious under the microscope. In the liver and muscles there is an actual increase of fat which has been transported in the blood from the normal sites of storage and has been taken up by the cells of these tissues. A similar active transference of fat from the depôts to the hungry cells takes place in starvation, but in this case the cells of the liver and muscles do not become loaded with fat; and this must be because they can metabolise it more rapidly. In poisoning by chloroform the cells are starving and call for fat which they take up more greedily than they can metabolise it ; and hence, whilst the transference of fatabout the body is increased, the metabolism of fat is decreased and we observe under the microscope a fatty infiltration of degenerated prote plasm.

These are the broad facts ; and Rosenfeld's interpretation of them has been hinted at and may now be shortly stated. He believes that when cells are poisoned by chloroform their metabolism is so altered that whilst they can utilise carbo hydrates well they can oxidise proteids but imperfectly and 